\title{
Intracardiac metastasis from known cervical cancer: a case report and literature review
}

\author{
Seung Won Byun', Sung Taek Park', Eun Young Ki', Hyun Song ${ }^{2}$, Suk Hee Hong ${ }^{3}$ and Jong Sup Park ${ }^{1 *}$
}

\begin{abstract}
Cardiac metastasis from known cervical cancer is rare. Even through a routine check-up, this type of metastasis can present as pulmonary emboli. Suspicion of this diagnosis in an oncology patient with complicating pulmonary emboli but no evidence of deep vein thrombosis is important, especially in cervical cancer patients with extensive pelvic lymph node metastasis and vascular invasion of a primary tumor. Early recognition may aid in improving the prognosis. We present a case of intracardiac metastasis arising from a squamous carcinoma of the cervix in a patient with pulmonary tumor emboli and review other cases from the literature.
\end{abstract}

Keywords: Cardiac carcinoma, Cervical cancer, Human papilloma virus, Metastasis, Pulmonary embolism, Recurrent

\section{Background}

Metastatic disease of the heart is rare. The incidence quoted in the current literature, based on autopsy, is approximately $1.23 \%$ [1]. The low incidence of cardiac metastasis is classically attributed to a combination of factors: continuous myocardial contraction, metabolic particularities of striated cardiac muscle, rapid flow of blood through the heart and lymph flow away from the heart [2].

Classically, there are four pathways of cardiac involvement: (1) retrograde lymphatic spread, (2) direct extension from the adjacent viscera, (3) hematogenous spread, and (4) transvenous extension through the vena cava into the right side chambers.

Myocardial involvement is much less common. It is usually the result of hematogenous spread, and is associated with widespread disseminated disease. Intracavitary, endocardial, or valvular metastatic deposits, such as the one described in our case, occur in less than $6 \%$ of cases [3]. Of particular interest, approximately $80 \%$ of this type of metastasis occurs in the right chambers and only rarely in the left chambers. This is attributed to the filtering role of the pulmonary circulation and the slower flow in the right chambers [4]. Clinical diagnosis of

\footnotetext{
* Correspondence: jspark@catholic.ac.kr

'Department of Obstetrics and Gynecology, Seoul St. Mary's Hospital, The Catholic University of Seoul, 505 Banpo-Dong, Seocho-Gu, Seoul 137-040, Korea

Full list of author information is available at the end of the article
}

cardiac metastases is difficult and may go unrecognized until autopsy.

We report a rare case of human papillomavirus (HPV)-detected metastatic intracardiac mass from known cervical cancer. The clinical, radiological and histological features are described. Simultaneously, the literature for all reports of these rare intracardiac metastases is reviewed.

\section{Case presentation}

A 32-year-old woman diagnosed in 2009 with International Federation of Gynecology and Obstetrics (FIGO) stage IIA2 cervical cancer(squamous cell carcinoma), presented to our hospital emergency room with exertional dyspnea lasting four days. The patient had previously received multimodality treatment from a multidisciplinary oncology group, which, because the patient was young and wanted to preserve ovarian function, included the following treatment: radical hysterectomy along with ovarian transposition and pelvic and para-aortic lymph node dissection and concurrent chemoradiation with six cycles of weekly cisplatin, including tomotherapy in pelvic and para-aortic lymph node area.

Thirteen months after completion of adjuvant treatment, 18-fludeoxyglucose positron emission tomographycomputed tomography (18-FDG PET-CT) revealed no evidence of recurrence. However, just two months later, she was examined on admission with chest $\mathrm{CT}$ 
(Figure 1A), which reported a finding of thromboemboli in several segmental branches of the right middle and lower lobe pulmonary arteries and in left lower lobe posterior basal segment arteries. Therefore, she was anticoagulated with warfarin and enoxaparin, a low-molecular-weight heparin. However, unfortunately, the patient still showed clinical deterioration with increasing shortness of breath and developed signs of rightheart strain, suggestive of further episodes of pulmonary embolism.

For evaluation of the embolic source, we performed echocardiography and deep vein thrombosis threedimensional CT (DVT 3D CT) angiography. The examinations revealed cardiac masses occupying the right ventricle and right atrium and no evidence of deep vein thrombus (Figure 1B).

In view of the threatened outflow obstruction caused by the right ventricular mass, the patient underwent an open excision of the intracardiac mass (Figure 2A). At the opening of the right atrium, whitish fungating, friable masses were seen arising from the free wall of the right atrium, extending through the tricuspid valve into the right ventricle. The masses were also seen arising from the free wall of the right ventricle through the opened tricuspid valve and occupied $90 \%$ of the right ventricular lumen, nearly resulting in right ventricle outflow tract obstruction. The masses were partially sucked out through suction tubes. The remnants of the masses were excised and collected. They were originally torn to pieces because the cardiac mass was so friable. Therefore, we fitted them together into one (Figure 2B).

The histopathology of the surgical specimen revealed this to be a cardiac metastasis from known cervical squamous cell carcinoma (Figure 3A). Additional HPV DNA genotyping of the metastatic lesion revealed HPV-16 consistent with the primary lesion. Cardiac metastasis should be the cause of the pulmonary embolic events and right heart failure that she had suffered.
After the patient's condition was stable, she was transferred to a medical oncologist for recurrence management. She underwent carboplatin with paclitaxel chemotherapy for palliative treatment at the medical oncology department. On a follow-up chest CT and echocardiogram after three cycles of the chemotherapy, cardiac mass and pulmonary thromboemboli were no longer seen. The patient was supposed to undergo six more cycles of the chemotherapy. She tolerated the chemotherapy well, but during the last month of her life, the recurrent cancer mass surrounding the celiac axis caused extensive hepatobiliary obstruction. The cancer mass in her heart was still regressed. She died of cachexia one year and four weeks from diagnosis of cardiac metastasis.

\section{Conclusion}

The clinical presentation may include nonspecific symptoms, such as chest pain, weight loss, malaise, or more characteristic symptoms, such as congestive cardiac failure secondary to intracardiac obstructions, valvular involvement, or pericardial effusions, arrhythmias due to involvement of the conduction system, or, as in our case, embolic events. Thus, metastases should be suspected in oncology patients if they develop inexplicable heart failure, neurological deficits, or recurrent pulmonary emboli, particularly when no peripheral source for the emboli can be identified.

Vascular invasion of primary cervical cancer is associated with hematogenous spread of cervical cancer (Figure 3B).

In our study, pathologic findings of primary cervical cancer showed vein and lymphatic invasion of squamous cell carcinoma with moderate differentiation. The authors suggest that the carcinoma of the cervix metastasized along the inferior vena cava to the heart, where it settled as an intracardiac obstructive mass. Pulmonary tumor emboli might decrease the right cardiac blood flow, resulting
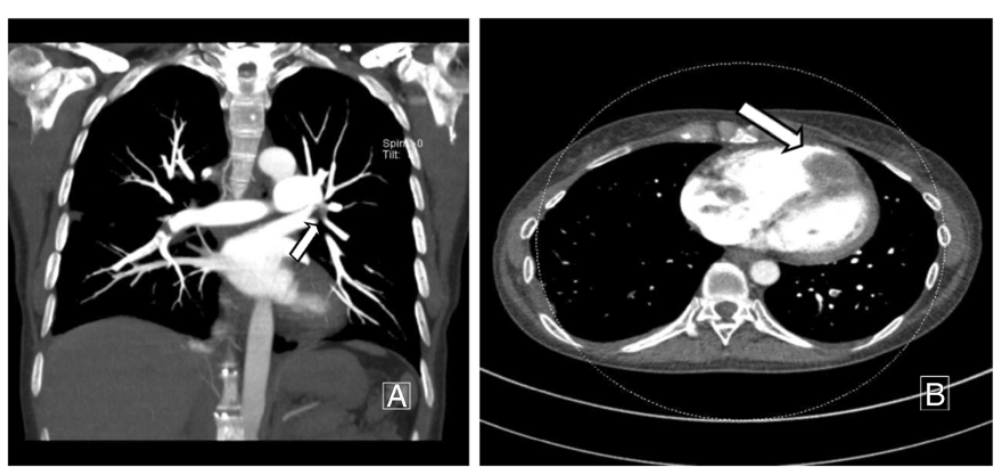

Figure 1 Deep vein thrombosis three-dimensional CT (DVT 3D CT) angiography showing the cardiac mass and thromboemboli before the surgery. (A) Maximum intensity projection (MIP) image shows pulmonary artery thromboembolism involving the right lower lobar artery and its segmental branches. (B) Computed tomography (CT) angiography of the pulmonary artery shows multiple large thrombi in the right atrium and right ventricle. 

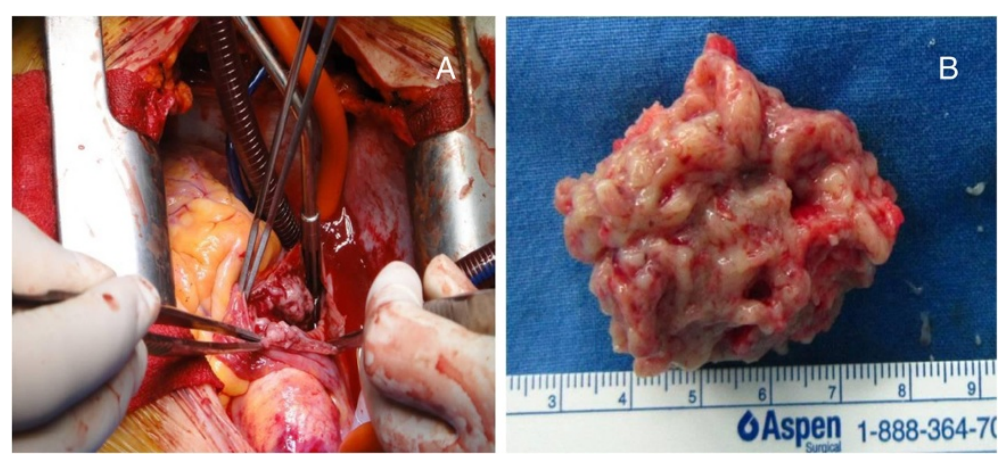

Figure 2 Pictures showing open right atrium and gross finding of cardiac mass. (A) The right atrium was open by cardiac incision. Cardiac masses invading the myocardium were seen. One of them protruded into the right ventricle through the tricuspid valve. However, the inferior vena cava was clear. Cardiac masses were also seen in the right ventricle and occupied $90 \%$ of the right ventricle lumen. All masses on the operation field were excised. (B) All materials from excised masses were collected. They were originally torn to pieces because the cardiac mass was so friable. Therefore, we fitted them together into one.

in a more hospitable environment for tumor cell adherence to the endocardial wall [5].

We searched PubMed between 1997 and 2011 and found nine articles, including the current case, which presented a clinical course and treatment of cardiac metastasis from known cervical cancer (Table 1) [6-12]. The average age of patients in these cases was 49.3 years old, the current case had the youngest patient who was 32 years old. While other cases didnot show any information about pathologic findings, our case showed identification of HPV DNA type 16 consistent with the primary tumor at the metastatic site. Yong Seok et al. suggested HPV status in the sentinel lymph node might be a prognostic factor in cervical cancer [13]. Yutaka et al. suggested that tumor-free, HPV DNA-positive metastatic sites should be monitored as being at high risk of relapse [14].

The role of HPV infection with a distant metastatic lesion is controversial. In a recent study, molecular analysis for HPV detection was performed in both uterine cervical cancer and right atrial cancer tissues. Both squamous cell carcinomas showed positivity for HPV, especially type 16 . Based on this result, the tumor in the right atrium favors a metastatic tumor from the uterine cervix.
To our knowledge and based on our literature search, an HPV-detected intracardiac mass has never been reported to be associated with recurrence of known cervical cancer.

Cardiac metastasis from cervical cancer is very rare and difficult to diagnosis. It causes acute severe heart failure,a life-threatening condition for which there is currently no standard treatment. After our review of the clinical courses of cardiac metastasis from cervical cancer, we suggest that patients with a high risk of recurrence must be carefully evaluated using echocardiography for cardiac metastasis, even if there are no symptoms.

Further studies may reveal the risk and aggravating factors for cardiac metastasis from cervical cancer, and may provide additional evidence to support our suggestion.

\section{Consent}

Written informed consent was obtained from the patient for publication of this case report and any accompanying images. A copy of the written consent is available for review by the Editor-in-Chief of this journal.

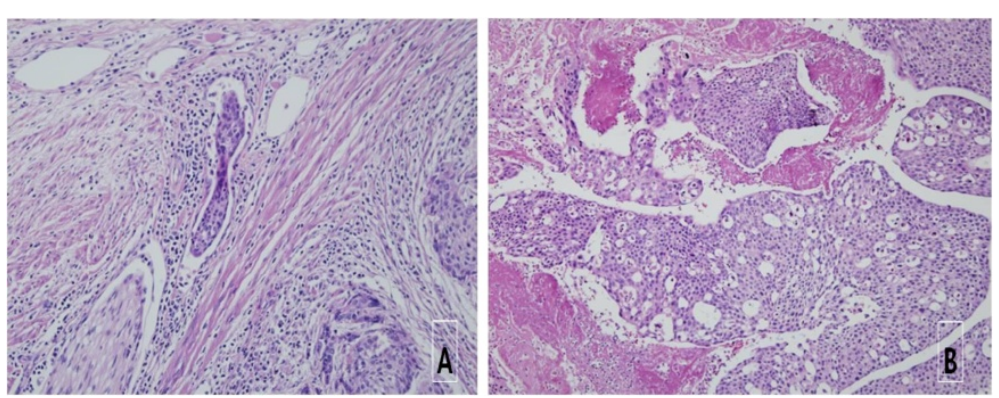

Figure 3 Microscopic findings showing primary cervical cancer and cardiac metastasis. (A) Microscopic findings of cervical squamous cell carcinoma (H\&E, $\times 200$ magnification). Vascular tumor emboli are observed adjacent to the tumor cell nest. (B) Microscopic finding of a right atrial mass. $(H \& E, \times 100)$ Squamous cell carcinoma in the right atrum shows the same histology as the cervix. The tumor involves the myocardium. 
Table 1 Literature review of cardiac metastasis from cervical cancer cases

\begin{tabular}{|c|c|c|c|c|c|c|c|c|c|c|c|c|}
\hline Author(year) & Age & Stage & Type & Primary $\mathrm{Tx}$ & $\begin{array}{l}\text { Interval } \\
\text { to cardiac } \\
\text { metastasis }\end{array}$ & $\begin{array}{l}\text { Recurrence } \\
\text { diagnosis } \\
\text { modality }\end{array}$ & Pathology confirmation by & Recurrence Tx & $\begin{array}{l}\text { Cause } \\
\text { of death }\end{array}$ & $\begin{array}{l}\text { Time to death } \\
\text { from cardiac } \\
\text { metastasis }\end{array}$ & $\begin{array}{l}\text { Chief complaint for } \\
\text { cardiac metastasis }\end{array}$ & $\begin{array}{l}\text { Overall } \\
\text { survival }\end{array}$ \\
\hline Ando et al. [6] & 41 & $\| \mathrm{B}$ & SCC & Op. & $8 \mathrm{M}$ & MRI scan & Autopsy & $C T x$ & RHF & $5 \mathrm{M}$ & Dyspnea & $13 \mathrm{M}$ \\
\hline Lemus et al. [7] & 53 & lb2 & SCC & Op. & $14 \mathrm{M}$ & MRI scan & Autopsy & CCRT & RHF & $1 \mathrm{M}$ & Dyspnea & $15 \mathrm{M}$ \\
\hline Lemus et al. [7] & 49 & IVB & SCC & ERT & $3 \mathrm{M}$ & MRI \& CT scan & No autopsy & CCRT & RHF & $7 \mathrm{M}$ & Dyspnea \&tachycardia & $13 \mathrm{M}$ \\
\hline Inamura et al. [8] & 58 & IB1 & SCC & $C T x$ & $44 \mathrm{M}$ & $\begin{array}{l}\text { Echocardiogram } \\
\text { and chest CT }\end{array}$ & Open excision & None & RHF & $4 \mathrm{M}$ & $\begin{array}{l}\text { Dyspnea \&purpura } \\
\text { of extremity }\end{array}$ & $48 \mathrm{M}$ \\
\hline Nakao et al. [9] & 57 & IIIB & SCC & CCRT & $10 \mathrm{M}$ & $\begin{array}{l}\text { Echocardiogram } \\
\text { and chest CT }\end{array}$ & Open excision & None & RHF & $2 \mathrm{M}$ & $\begin{array}{l}\text { Mild chest pain \& } \\
\text { shortness of breath }\end{array}$ & $12 \mathrm{M}$ \\
\hline Borsaru et al. [10] & 42 & IVB & SCC & CCRT & $6 \mathrm{M}$ & $\begin{array}{l}\text { Echocardiogram } \\
\text { and chest CT }\end{array}$ & Open excision & * & * & * & * & * \\
\hline Kim et al. [11] & 64 & IB1 & SCC & CCRT & $5 \mathrm{M}$ & $\begin{array}{l}\text { Echocardiogram, } \\
\text { TEE and chest CT }\end{array}$ & Pericardiocentesis & $C T x$ & RHF & $7 \mathrm{M}$ & Dry cough\&dyspnea & $12 \mathrm{M}$ \\
\hline Miller et al. [12] & 48 & lb2 & Adeno & CCRT & $48 \mathrm{M}$ & MRI scan & $\begin{array}{l}\text { Transesophageal } \\
\text { echocardiography- guided } \\
\text { biopsy }\end{array}$ & $\mathrm{CT} x / \mathrm{RT}$ & RHF & $8 \mathrm{M}$ & Chest pain & $56 \mathrm{M}$ \\
\hline Current study (2011) & 32 & $\| \mathrm{A}$ & SCC & Op. & $15 \mathrm{M}$ & $\begin{array}{l}\text { Echocardiogram } \\
\text { and chest CT }\end{array}$ & Open excision & $C T x$ & Cachexia & $13 \mathrm{M}$ & $\begin{array}{l}\text { Dyspnea \&purpura } \\
\text { of extremity }\end{array}$ & $32 \mathrm{M}$ \\
\hline
\end{tabular}

*no available data. Adeno, adenocarcinoma; CCRT, concurrent chemoradiotherapy; CT, computed tomography; CTx, chemotherapy;ERT, external radiotherapy; M, months; MRI, magnetic resonance imaging; Op., operation; RHF, right heart failure; SCC, squamous cell carcinoma; TEE, transesophageal.Echocardiogram; Tx, therapy. 


\section{Competing interests}

The authors declare that they have no competing interests.

\section{Authors' contribution}

SWB contributed mainly to the design, literature review and the writing of the work. JSP, the corresponding author who provided the case, planned and approved the written work. STP and EYK helped correct the manuscript. HS performed the cardiac surgery and described the operative finding. SHH performed the palliative chemotherapy on the patient and edited the discussion. All authors read and approved the final manuscript.

\section{Author details}

'Department of Obstetrics and Gynecology, Seoul St. Mary's Hospital, The Catholic University of Seoul, 505 Banpo-Dong, Seocho-Gu, Seoul 137-040, Korea. ${ }^{2}$ Department of Thoracic Surgery, Seoul St. Mary's Hospital, The Catholic University of Seoul, 505 Banpo-Dong, Seocho-Gu, Seoul 137-040, Korea. ${ }^{3}$ Department of Medical Oncology, Seoul St. Mary's Hospital, The Catholic University of Seoul, 505 Banpo-Dong, Seocho-Gu, Seoul 137-040, Korea.

Received: 5 November 2012 Accepted: 9 May 2013

Published: 23 May 2013

\section{References}

1. Grigsby PW: The prognostic value of PET and PET/CT in cervical cancer. Cancer Imaging 2008, 8:146-155.

2. Jann H, Wertenbruch T, Pape U, Ozcelik C, Denecke T, Mehl S, Wiedenmann $B$, Pavel M: A matter of the heart: myocardial metastases in neuroendocrine tumors. Horm Metab Res 2010, 42:967-976.

3. Mukai K, Shinkai T, Tominaga K, Shimosato Y: The incidence of secondary tumors of the heart and pericardium: a 10-year study. Jpn J Clin Oncol 1988, 18:195-201.

4. Lam KY, Dickens P, Chan AC: Tumors of the heart. A 20-year experience with a review of 12,485 consecutive autopsies. Arch Pathol Lab Med 1993, 117:1027-1031.

5. Sergi C, Magener A, Ehemann V, De Villiers EM, Sinn HP: Stage lla cervix carcinoma with metastasis to the heart: report of a case with immunohistochemistry, flow cytometry, and virology findings. Gynecol Oncol 2000, 76:133-138.

6. Ando K, Kashihara K, Harada M, Kasem I, Nishitani H, Sano N, Ohtani T: Carcinoma of the uterine cervix with myocardial metastasis. Gynecol Oncol 1997, 65:169-172.

7. Lemus JF, Abdulhay G, Sobolewski C, Risch VR: Cardiac metastasis from carcinoma of the cervix: report of two cases. Gynecol Oncol 1998, 69:264-268.

8. Inamura K, Hayashida A, Kaji Y, Ito H, Hirakawa T, Kobayashi H, Masuda M, Nishida T, Harada M: Recurrence of cervical carcinoma manifesting as cardiac metastasis three years after curative resection. Am J Med Sci 2004, 328:167-169.

9. Nakao Y, Yokoyama M, Yasunaga M, Hara K, Nakahashi H, Iwasaka T: Metastatic tumor extending through the inferior vena cava into the right atrium: a case report of carcinoma of the uterine cervix with para-aortic lymph node metastases. Int J Gynecol Cancer 2006, 16:914-916.

10. Borsaru AD, Lau KK, Solin P: Cardiac metastasis: a cause of recurrent pulmonary emboli. Br J Radiol 2007, 80:e50-e53.

11. Kim HS, Park N-H, Kang S-B: Rare metastases of recurrent cervical cancer to the pericardium and abdominal muscle. Arch Gynecol Obstet 2008, 278:479-482.

12. Miller ES, Hoekstra AV, Hurteau JA, Rodriguez GC: Cardiac metastasis from poorly differentiated carcinoma of the cervix: a case report. J Reprod Med 2010, 55:78-80.
13. Lee YS, Rhim CC, Lee KH, Park JS, Namkoong SE: HPV status in sentinel nodes might be a prognostic factor in cervical cancer. Gynecol Oncol 2007, 105(2):351-357.

14. Nagai Y, Maehama T, Asato T, Kanazawa K: Detection of human papillomavirus DNA in primary and metastatic lesions of carcinoma of the cervix in women from Okinawa, Japan. Am J Clin Oncol 2001, 24(2):160-166.

doi:10.1186/1477-7819-11-107

Cite this article as: Byun et al:: Intracardiac metastasis from known cervical cancer: a case report and literature review. World Journal of Surgical Oncology 2013 11:107.

\section{Submit your next manuscript to BioMed Central and take full advantage of:}

- Convenient online submission

- Thorough peer review

- No space constraints or color figure charges

- Immediate publication on acceptance

- Inclusion in PubMed, CAS, Scopus and Google Scholar

- Research which is freely available for redistribution

Submit your manuscript at www.biomedcentral.com/submit
C) Biomed Central 